\title{
Process Improvement through Developing Drill Jig for Manufacturing of Konkurs-M Missile Component (Cover)
}

\section{Dr.M.Harinath Reddy}

\begin{abstract}
The project study is about developing a jig for holding and drilling the 'cover' component for mass production. This report begins with the introduction of jigs which is the definition of important components in jigs and advantages of jigs. Drill jig increases productivity by eliminating individual marking, positioning and frequent checking. Mass production targets on increasing productivity and increasing accuracy by reducing the setup cost and manual fatigue. One of the common practices to achieve the goals of mass production is to use jigs. Drill jig increases productivity by eliminating individual marking, positioning and frequent checking. Inter changeability is one of the advantages of jigs.
\end{abstract}

Index Terms-Drill jig, Cover component, Locking screw.

\section{INTRODUCTION}

Mass production targets on increasing productivity and increasing accuracy by reducing the setup cost and manual fatigue. One of the common practices to achieve the goals of mass production is to use jigs. Let us consider an example that one gets an order of 1000 product in such a way that three holes are to be drilled in a work piece. In such situations, designer will lay out the position of each hole with the help of square, straightness, scribers, centre punch etc. Generally, trial and error method is practiced until the axis of hole is properly aligned with the axis of drill. Thus, a lot of time will be consumed to maintain the accuracy. Ultimately it increases operator's fatigue. Thus, instead of laying out the position of each hole on each workpiece with the aid of square, straightness, scribers, centre punch etc., the operator uses a jig to position and guide the drill into proper place.

\subsection{Introductions to jigs:}

Jig can be defined as a work piece holding and locating device that positions and guides or controls the cutting tool. A jig reduces the repetitive nature required for drilling a hole, as the locating, clamping and guiding are done by jig itself. The tool-guiding element helps in setting of tool in correct position. Hence, skilled workers are not required. The most-common jigs are drill and boring jigs. These tools are

Dr.M.Harinath Reddy, Professor Department of mechanical engineering, Gurunanak institutions technical campus, Hyderabad, India. fundamentally the same. The difference lies in the size, type, and placement of the drill bushings. Boring jigs usually have larger bushings. These bushings may also have internal oil grooves to keep the boring bar lubricated.

\subsubsection{Elements of jigs:}

Jig generally consists of locating element, clamping element and tool guiding or setting element.

Locating Elements:

Locating elements position the work piece accurately with respect to tool guiding elements in the jig.

\section{Clamping Elements:}

Clamping elements hold the work piece securely in the located position during operation.

Tool Guiding Elements:

Tool guiding elements help in guiding the tools in correct position with respect to the work piece. Drill bushes guide the drills accurately to the work piece.

\subsection{Importance of jigs:}

Jigs are very important in manufacturing industry. These tools make sure that manufacturing process in production line going smooth and easier to operator doing their job. Jig helps operator to holding part which will be processing or in operation. In production rate, using jigs increased the productivity because it will minimize the production time.

\subsubsection{ADVANTAGES: \\ (i) Productivity: \\ (ii) Interchangeability: \\ (iii) Skill reduction: \\ (iv) Cost reduction:}

\subsection{Introduction to drill jigs:}

Drill jig is a device to ensure a hole to be drilled, tapped or reamed in the workpiece at proper place .Drill jig consists of a clamping device to hold the part in the position under hardened steel bushings. Drill passes through the steel bushings during drilling operation. The drill is guided by these bushings. Generally workpiece is held by jig and the jig is arranged in such a way that the workpiece can be quickly loaded and unloaded.

In the drill jigs, locating and clamping elements are subjected to high torque in the direction perpendicular to the axis of the cutting tool. The jigs and the work-piece are also subjected to thrust in the direction of the feed of the tool. To produce a 
good jig it must fulfill certain requirements. The jigs must be quick and accurate in location of the work-piece.

Otherwise, the jigs that are designed must be easy to load and unload the work-piece and prevent wrong loading, also prevent the bending or movement of the work piece during drilling process. For an efficient jig design, it must have an ample chip clearance with facilities for scarf removal and cleaning.

In the jig design, weight is an important factor to consider before production. Light weight is needed to minimize operator fatigue due to repeated handling. Otherwise, prevention of loss of loose parts by chaining them to the jig body and clearance for overshoot of the drill must be prepared.

\subsubsection{TYPES OF DRILL JIGS:}

Depending upon method of operation and construction, drill jigs can be broadly classified as:
(a)Plate Jig
(b)Leaf jig
(c)Box jig
(d)Indexing jig

\section{MATERIALS AND MANUFACTURING PROCESS OF COVER COMPONENT}

3.1 objectives:

To develop a drill jig for effective manufacturing of a KONKURS-Missile component (cover).

\subsection{Earlier operations:}

The operation was earlier done using a 5-axis CNC milling machine (TAJMAC-5AXIS) which was increasing the manufacturing cost, over loading work on the 5-axis CNC machine (TAJMAC-5 axis) and increasing the power consumption.

\subsection{Operating sequence:}

The component is made of ALUMINIUM alloy. The component was first turned in the turning section in CNC shop which is then worked on CNC machine.The desired component is produced after several machining operations according to the programming function.

The component surface was to be milled with four lobes on a CNC machine and also the eight holes at an angle on the surface along the perimeter are to be drilled after milling operation.
TABLE 3.1 LIST OF COMPONENTS :

\begin{tabular}{|c|c|c|c|}
\hline $\begin{array}{l}\text { S.N } \\
\text { O. }\end{array}$ & COMPONENT & MATERIAL & $\begin{array}{l}\text { QUANTIT } \\
\mathrm{Y}\end{array}$ \\
\hline 1 & BASE & M.S & 1 \\
\hline 2 & TOP PLATE & M.S & 1 \\
\hline 3 & $\begin{array}{l}\text { ROTATING } \\
\text { CENTRE } \\
\text { PIECE }\end{array}$ & M.S & 1 \\
\hline 4 & $\begin{array}{l}\text { SUPPORTIN } \\
\text { G BLOCK }\end{array}$ & M.S & 1 \\
\hline 5 & $\begin{array}{l}\text { LOCKING } \\
\text { PIN }\end{array}$ & M.S & 1 \\
\hline 6 & SPRING & $\begin{array}{l}\text { STANDARD } \\
\text { PART }\end{array}$ & 1 \\
\hline 7 & $\begin{array}{l}\text { DOWEL } \\
\text { PINS ( } \emptyset 5 \times \\
20)\end{array}$ & $\begin{array}{l}\text { STANDARD } \\
\text { PART }\end{array}$ & 4 \\
\hline
\end{tabular}

3.4 Experimental details

3.4.1 Development of drill jig:

We with the help of BDL TEAM, developed a drill jig to meet the requirement of drilling holes on the component on a bench drilling machine which was earlier done on a $\mathrm{CNC}$ machine there by decreasing the high cost of manufacturing involved. A CNC machine needs a costly AlC setup and a skilled operator is required. The machine consumes high power and causes over work load on the machine and operator. 
To reduce this a drill jig of the given shape, dimensions as shown in the figure was developed and the process was successfully proved, Thus simplified.

\subsubsection{After operation:}

A preliminary drafting of the drill jig is made based on the idea of various jigs available as mentioned earlier in the literature survey. Based on an indepth analysis on the constraints involved in the requirement of the jig and also the considerations required to design based on the type of operation a desired and a sustainable design is proposed.

A drill jig of required dimensions and for the operation required is designed with the help of BDL team .

\subsubsection{Drill jig explanation:}

The body of the jig is made of MS material. It is made sturdy and heavy enough to withstand the drilling loads as well as to reduce wear and to have a longer life time. It consists of a top plate in which two holes and bushes are used to locate and guide the component during operation. The holes are made normal to the inclination of the surface of the component.

Components of Drill Jig :

\section{Base}

Rotating Centre piece

Top plate

Supporting block

Locking screw

The base is made of MS with the top surface inclined at an angle equal to the taper angle with which the holes are to be drilled. The base is made robust to take all the vibrations and shock loads during the operation on a bench drilling machine.

A rectangular Top plate is fixed on the top surface of the drill jig with the help of dowel pins and screws. This plate consists of two bushes that guide the drill bit to perform the operation.The diameter of the bush is selected with close tolerences in order to attain accuracy of the holes to be drilled.

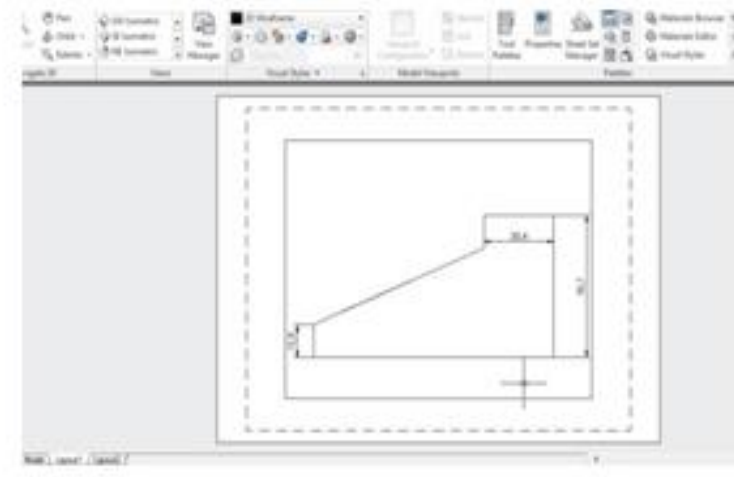

Fig 3.4.1 Side view of Base

The central element holds the component in position and it can be rotated in position and it can be rotated about its own axis to dril holes on the periphery of the component surface.

A locking pin is used to arrest the rotation of central element. It is located with the help of the screws, and a spring is used to restore its position. This screw is guided by a square block that is fixed to the base using dowel pins and screws

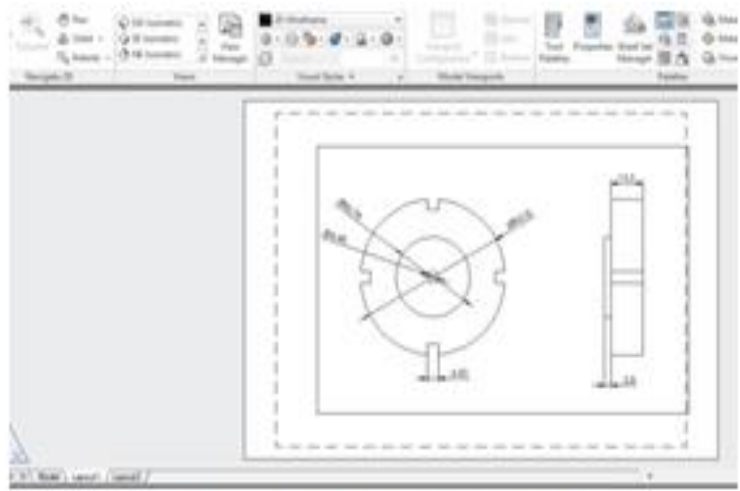

Fig 3.4.2 Rotating centre piece

This drill jig has got many advantages. The power consumption is considerably reduced by using the traditional bench drilling machine and a skilled worker is not essential.

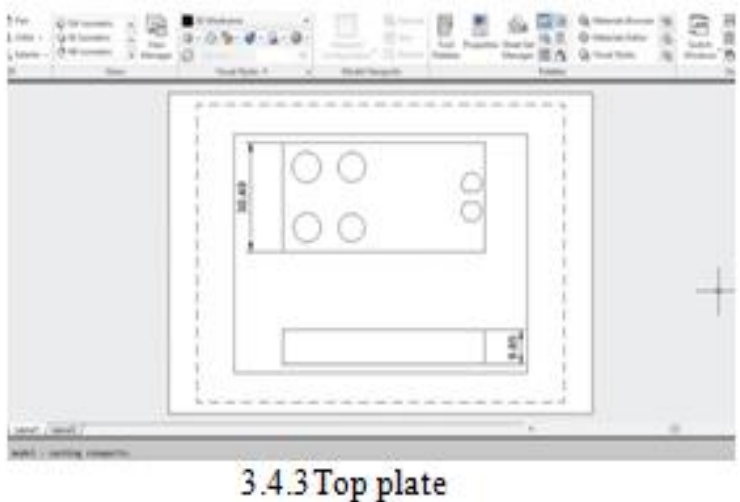

The following drill jig is used for the manufacturing of 
missile component "cover" which is the most crucial part of the missile(KONKURS-M).

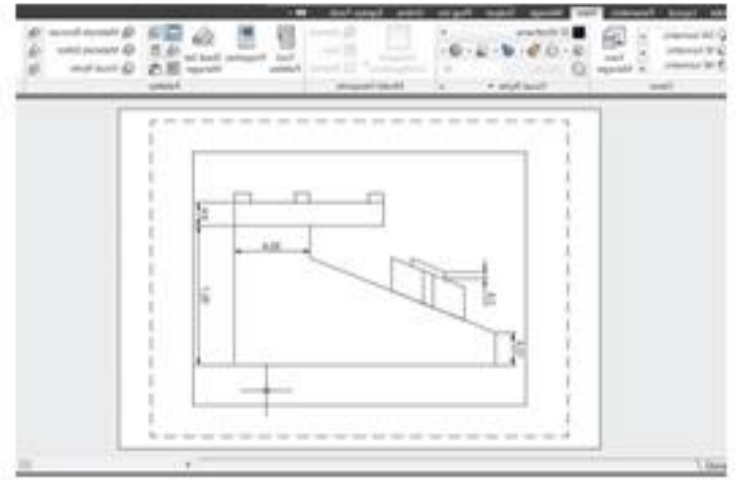

Fig 3.4.4. Side view of Drill jig

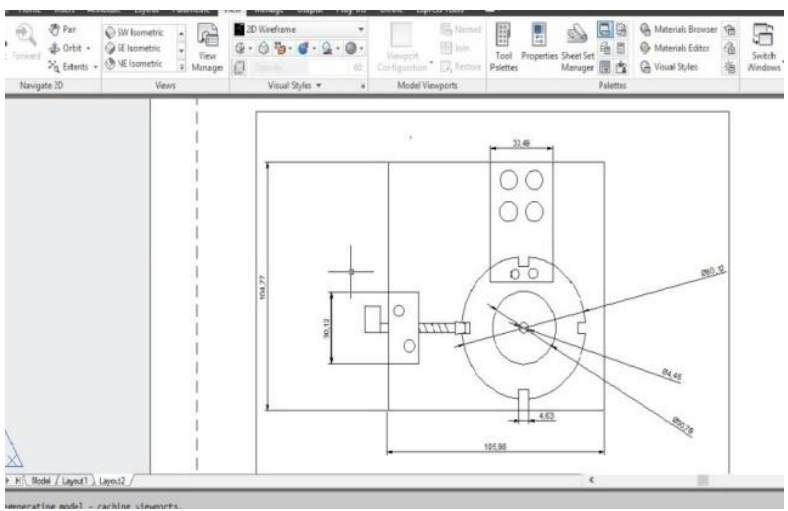

Fig 3.4.5 Top view of drill jig

3.5 Procedure of cover:

- Hold the component which is milled in the 5-axis CNC milling machine in the drill jig by placing it between the rectangular plate and the rotating centre piece.

- The Rotating centre piece is provided with two pins that hold the work piece and arrests the motion of the component on the rotating centre piece.

- Now, arrest the motion of the Rotating Centre piece using locking screw,ensure the location of the holes to be drilled on the surface of the component is aligned with the bushes of the top plate.

- Drill the holes of required dimensions normal to the surface of the component.
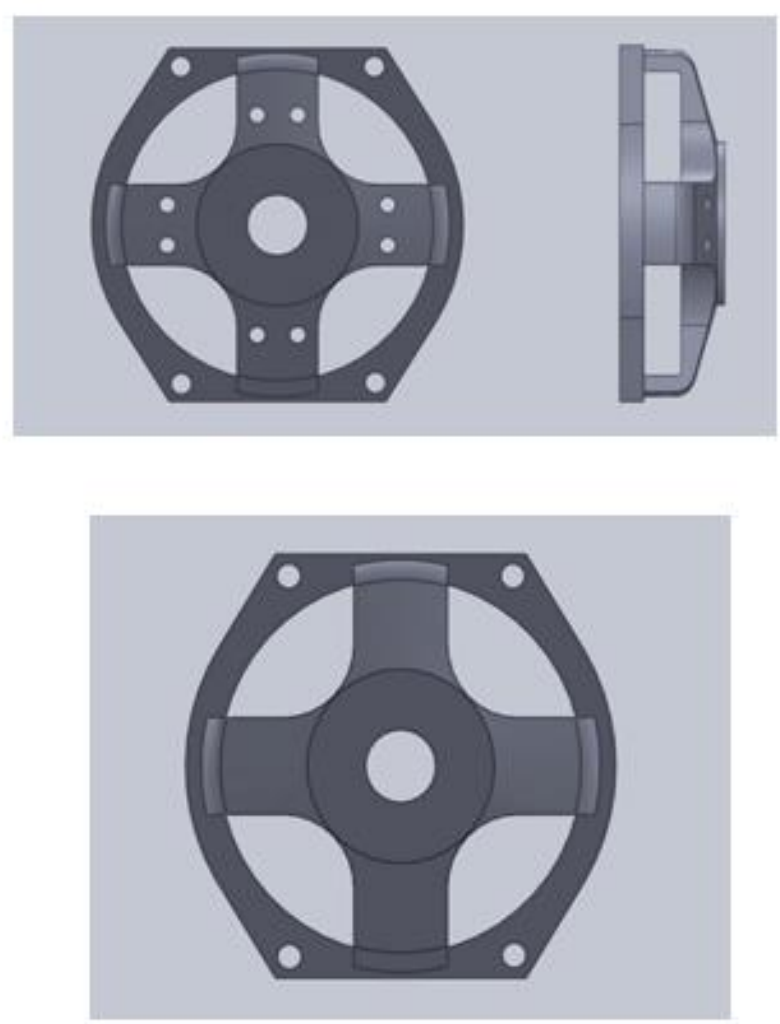

Fig 3.5.1 Before Drilling Operation

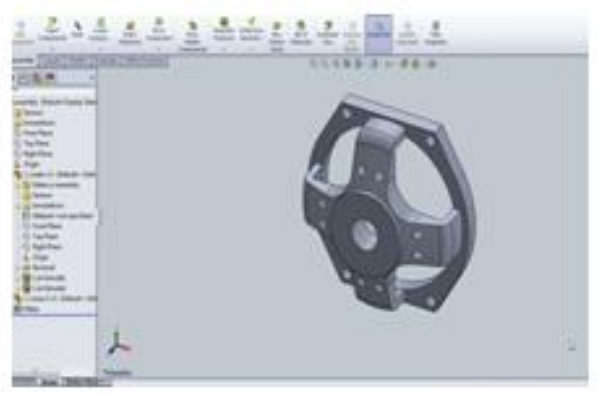

Fig 3.5.2 After hole Drilling Operation

IV. CONCLUSIONS

The following are the conclusions drawn:

1. The drill jig was successfully developed and proved for manufacturing of COVER component.

2. The cost of machines can be reduced from a highly expensive TAJMAC 5-AXIS CNC milling machine to Bench Drilling machine

3. A CNC skilled operator is not required.

4. To OFF-LOAD the work from an expensive $\mathrm{CNC}$ milling machine.

5. Cost of manufacturing is drastically reduced due to simple bench drilling machine.

6. High power consumption is reduced.

7. Costly AlC setup is not required. 
International Journal of Engineering and Applied Sciences (IJEAS)

ISSN: 2394-3661, Volume-7, Issue-1, January 2020

\section{REFERENCES}

[1] PRODUCTION TECHNOLOGY by HMT PUBLICATIONS.

[2] WORKSHOP TECHNOLOGY by HAJRA CHOUDHARY

[3] MANUFACTURING TECHNOLOGY by P.N RAO

[4] https://en.wikipedia.org/wiki/Jig_\%28tool\%29

[5] Henriksen, Erik Karl (1973), Jig and fixture design manual, Industrial Press, ISBN 978-0-8311-1098-7.

[6] www.google.co.in/patents/US2728249

[7] https://www.google.com/patents/US2898785

[8] patents.justia.com/patents-by-us-classification/408/115R 